\title{
Size-dependent activation of aerosols into cloud droplets at a subarctic background site during the second Pallas Cloud Experiment (2nd PaCE): method development and data evaluation
}

\author{
T. Anttila ${ }^{1}$, P. Vaattovaara ${ }^{2}$, M. Komppula ${ }^{3}$, A.-P. Hyvärinen ${ }^{1}$, H. Lihavainen ${ }^{1}$, V.-M. Kerminen ${ }^{1}$, and A. Laaksonen ${ }^{1,2}$ \\ ${ }^{1}$ Finnish Meteorological Institute, P.O. Box 503, 00101 Helsinki, Finland \\ ${ }^{2}$ Department of Physics, University of Kuopio, P.O. Box 1672, 70211 Kuopio, Finland \\ ${ }^{3}$ Finnish Meteorological Institute, Kuopio Unit, P.O. Box 1627, 70211 Kuopio, Finland
}

Received: 7 May 2009 - Published in Atmos. Chem. Phys. Discuss.: 30 July 2008

Revised: 5 June 2009 - Accepted: 12 July 2009 - Published: 22 July 2009

\begin{abstract}
In situ measurements of aerosol water uptake and activation of aerosols into cloud droplets provide information on how aerosols influence the microphysical properties of clouds. Here we present a computational scheme that can be used in connection with such measurements to assess the influence of the particle hygroscopicity and mixing state (in terms of the water uptake) on the cloud nucleating ability of particles. Additionally, it provides an estimate for the peak supersaturation of water vapour reached during the formation of the observed cloud(s). The method was applied in interpreting results of a measurement campaign that focused on aerosol-cloud interactions taking place at a subarctic background site located in Northern Finland (second Pallas Cloud Experiment, 2nd PaCE). A set of case studies was conducted, and the observed activation behavior could be successfully explained by a maximum supersaturation that varied between 0.18 and $0.26 \%$ depending on the case. In these cases, the diameter corresponding to the activated fraction of $50 \%$ was in the range of $110-140 \mathrm{~nm}$, and the particles were only moderately water soluble with hygroscopic growth factors varying between 1.1 and 1.4. The conducted analysis showed that the activated fractions and the total number of particles acting as $\mathrm{CCN}$ are expected to be highly sensitive to the particle hygroscopic growth properties. For example, the latter quantity varied over a factor between 1.8 and 3.1, depending on the case, when the mean hygroscopic growth factors were varied by $10 \%$. Another important conclusion is that size-dependent activation profiles carries information on the mixing state of particles.
\end{abstract}

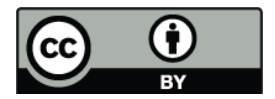

Correspondence to: $\mathrm{T}$. Anttila (tatu.anttila@fmi.fi)

\section{Introduction}

Largest uncertainties in the current predictions regarding the climate change arise from the influence of aerosols on the microphysical properties of clouds (IPCC, 2007). This underscores the need to improve our knowledge on the connections between the atmospheric aerosols and clouds (Ghan and Schwartz, 2007; Lohmann et al., 2007). To address this issue, several advances in theoretical understanding of the cloud formation have been made during the recent years, and many of the results have been incorporated into large-scale climate models as computationally efficient parameterizations (Chen and Penner, 2005; McFiggans et al., 2006 and references therein). However, further experimental studies involving insitu measurements of aerosols and their activation into cloud droplets are still warranted to refine microphysical models as well as the resulting parameterizations (Ghan and Schwartz, 2007).

Ground-based measurements of activation of ambient aerosols are typically based on a separate determination of "interstitial" and "residual" fractions of aerosols. The former refers to those particles that did not participate in the cloud formation, whereas the latter acted as cloud condensation nuclei $(\mathrm{CCN})$ and thus grew through condensation of water vapor to notably larger diameters, i.e. over an order of magnitude, than interstitial particles. Using such an experimental setup, the fraction of particles that are activated into cloud droplets can be inferred. Size-resolved measurements, if available, provide further insights into aerosol activation through allowing for investigating size-dependent particle activation characteristics (e.g. Svenningsson et al., 1994; Henning et al., 2002; Komppula et al., 2005; Targino et al., 2007).

Published by Copernicus Publications on behalf of the European Geosciences Union. 
Size-resolved measurements on the cloud scavenging of ambient particles can be complemented by determining the particle water uptake properties by using e.g. a Hygroscopic Tandem Differential Mobility Analyzer (H-TDMA) that is used to measure the hygroscopic growth of particles as a function of time and particle size (McMurry, 2000). HTDMA measurements allow for investigating the influence of the particle water-solubility and they provide also information on the particle mixing state in terms of the water uptake. Such information is valuable because the particle hygroscopicity and mixing state are expected to play a large role in the cloud nucleating ability of atmospheric particles (McFiggans et al., 2006). Furthermore, on the basis of activation and H-TDMA measurements the fraction of particles capable of acting as CCN can be determined as a function of the water vapour supersaturation by applying Köhler theory. A comparison of the predicted size-dependent activation curves with the measurement results has been shown to give insight into the peak supersaturation reached during the cloud formation, on the adiabacity of the sampled cloud air and also on the possible presence of organic films on the particles (Svennigsson et al., 1994, 1997; Mertes et al., 2005).

Several computational tools have been developed to aid interpretation of the experimental data on the water uptake properties of particles with varying physico-chemical properties (e.g. Rissler et al., 2004; Kreidenweis et al., 2005; Gasparini et al., 2006; Padró et al., 2007; Petters and Kreidenweis, 2007; Ziese et al., 2008). These frameworks have been motivated by $\mathrm{CCN}$ measurements where particles are exposed to a known water vapour supersaturation and are often used to interpret laboratory experiments where the particle chemical composition is more constrained compared to variability exhibited by atmospheric particles. On the other hand, parameterizations of cloud droplet formation during an ascent of a convective air parcel require the updraft velocity of the air parcel as an input (Abdul-Razzak and Ghan, 2000; Cohard et al., 2000; Nenes and Seinfeld, 2003; Ming et al., 2006), a quantity which is difficulty to determine in ground based studies (Verheggen et al., 2007). To the best of our knowledge, no comprehensive computational scheme that would be applicable to studies on activation of ambient particles using the above described experimental setup is presented in the literature.

The current study addresses the above-mentioned gaps in the literature by developing and applying a method that is suitable for analyzing size-resolved data on atmospheric aerosols, their activation characteristics and hygroscopic properties. To be more explicit, our goals are to: 1) present a simple computational procedure which allows for calculating the activated fractions of particles based on the Köhler theory and information on the particle hygroscopicity, 2) derive expressions for estimating the maximum supersaturation of water vapour and for calculating $\mathrm{CCN}$ spectra, and 3) apply the developed framework to interpreting results of a measurement campaign that focused on aerosol-cloud interactions taking place at a subarctic background site (Komppula et al., 2006).

The paper is organized as follows. In Sect. 2, the computational procedure is derived and some additional issues that arise when applying the method are discussed. The relevant measurements carried out during the measurement campaign are briefly described in Sect. 3. The results of the data analysis are given in Sect. 4, and the summary and conclusions follow in Sect. 5.

\section{Model approach}

\subsection{General formulation}

We consider a situation where there are size-segregated measurements for the particle number concentration and for the activated fraction of particles, $C N_{\text {tot }, 1}, C N_{\text {tot }, 2}, \ldots, C N_{\text {tot, } N}$ and $A F_{1}, A F_{2}, \ldots, A F_{N}$, respectively. The corresponding particle dry diameters are denoted by $d_{p, 1}, d_{p, 2}, \ldots, d_{p, N}$. To start with, we assume that no entrainment took place during the measurements. We also assume that the hygroscopic properties of particles have been measured for a number of particle sizes. If the diameters at which the measurements were conducted do not overlap with the diameters $d_{p, 1}, d_{p, 2}$ $, \ldots, d_{p, N}$, the measured hygroscopic properties need to be extra- or interpolated to these diameters (see Sect. 4.2. for example). For the purposes of this study, it is convenient to characterize the hygroscopic properties by the normalized cumulative distributions of the hygroscopic growth $(\mathrm{HG})$ factors, $G R_{1}, G R_{2}, \ldots, G R_{N}$. To be explicit, $G R_{i}(g)$ gives the fraction of particles in the size bin $i$ that have a HG factor smaller than $g$. As seen later, the activated fraction of particles can be treated also as a cumulative distribution, and this makes the use of cumulative HG distributions convenient. The distributions $G R_{i}$ can be obtained through a fitting procedure. It should be noted that the approach does not involve any assumptions regarding the shape of the humidified distributions, and thus it allows for considering a case where particles with the same dry size exhibit a variety of water uptake properties. The list of the key symbols used in this section is given in Appendix A.

Köhler theory states that those particles/droplets whose critical supersaturation, $s_{c}$, is lower than the ambient supersaturation of water are activated, i.e. they grow spontaneously through condensation of water vapour (Seinfeld and Pandis, 1998). The normalized cumulative distributions of the fraction of particles in a size class $i$ that are activated at a supersaturation $s, K_{i}(s)$, can be formulated as follows:

$K_{i}(s)=\frac{C N_{i}\left(s_{c}<s\right)}{C N_{\mathrm{tot}, i}}$,

where $C N_{i}\left(s_{c}<\mathrm{s}\right)$ is the number of particles having a critical supersaturation below $s$ in the size class $i, i=1, \ldots$, $N$. We first derive an expression for the fraction of activated 
particles in the size bin $i, A F_{i}^{*}$, and then present how the maximum supersaturation reached during the formation of observed cloud(s) can be estimated by calculating activated fractions $A F_{i}^{*}$ in each size bin $i$. Here we assume that those, and only those, particles which have a critical supersaturation below a value $s_{\max }$ contribute to the droplet population of a cloud formed under the maximum supersaturation $s_{\max }$. Consequently, $A F_{i}^{*}$ and $K_{i}$ are equal, i.e. $A F_{i}^{*}=K_{i}$. This assumption is not necessarily true due to the dynamic nature of the atmospheric cloud formation, however. The validity of the assumption will be discussed in Sect. 2.2.

Next we utilize information on the particle hygroscopic properties by expressing the distribution $K_{i}$ in terms of $G R_{i}$. This is achieved by first relating $G R_{i}$ and the cumulative distribution of the soluble volume fractions of particles in the size bin $i, S F_{i}$. According to the definition, $S F_{i}(v)$ is the fraction of particles in the size bin $i$ that contain less water-soluble volume than $v$. In the next step, Köhler theory is used to relate the water-soluble volume fraction and the particle critical supersaturation. To this end, the water uptake of particles is modeled by assuming that the dry particle mass consists of two components: water-soluble and waterinsoluble fractions, and that the former component exhibits similar hygroscopic behavior than ammonium sulfate at subsaturated conditions. It should be noted that the following results are not sensitive to the choice of the model compound provided that its properties are used consistently in calculations (Rissler et al., 2004). According to this scheme the soluble volume fraction of a particle, $\varepsilon$, is related to its $\mathrm{HG}$ factor, $g f$, as follows (e.g. Swietlicki et al., 1999):

$\varepsilon=\frac{g f^{3}-1}{c\left(a_{w}\right)}, c\left(a_{w}\right)=g f_{A S}^{3}\left(a_{w}\right)-1$.

Here $a_{w}$ is the water activity at which the particle hygroscopic growth was measured or estimated and $g f_{A S}\left(a_{w}\right)$ is the growth factor of ammonium sulfate particle at the water activity $a_{w}$. Equation (2) allows for converting HG factors to the corresponding soluble volume fractions. By doing this, the sought relation between $G R_{i}$ and $S F_{i}$ is obtained:

$$
\begin{aligned}
& S F_{i}(\varepsilon)=G R_{i}\left[g f_{i}(\varepsilon)\right], \\
& g f_{i}(\varepsilon)=\left(c_{i} \varepsilon+1\right)^{1 / 3}, \\
& c_{i}=c\left(a_{w, i}\right) .
\end{aligned}
$$

Here $a_{w, i}$ is the water activity at which the hygroscopic properties of particles in the size bin $i$ were measured or estimated. Brackets are used in Eq. (3) to indicate that the argument of $G R_{i}$ is another function, $g f_{i}$, which maps a soluble volume fraction $\varepsilon$ to the corresponding HG factor. On the other hand, Köhler theory provides a link between the particle water solubility, parameterized here with $\varepsilon$, and the particle critical supersaturation, $s_{c}$ (Seinfeld and Pandis, 1998):

$$
\begin{aligned}
& s_{c} \approx k \varepsilon^{-1 / 2} d_{p}^{-3 / 2}, \\
& k=2\left(\frac{4}{3 R T}\right)^{3 / 2}\left(\frac{M_{w}}{\rho_{w}}\right)\left(\frac{M_{s}}{v \phi \rho_{s}}\right)^{1 / 2} \sigma^{3 / 2} .
\end{aligned}
$$

Here $d_{p}$ is the dry particle diameter, $\sigma$ is the particle surface tension, $M_{s}, v \phi$, and $\rho_{s}$ are the molecular weight, the "effective" number of ions into which a solute molecule dissociates (the van't Hoff factor) and the density of ammonium sulfate, respectively. In addition, $R$ is the ideal gas constant, $T$ is the temperature, and $M_{w}$ and $\rho_{w}$ are the molecular weight and density of water, respectively. According to the definitions of $S F_{i}$ and $K_{i}, K_{i}$ can be expressed in terms of $S F_{i}$ as follows: $K_{i}(s)=1-S F_{i}\left(\varepsilon^{*}\right)$ where $\varepsilon^{*}$ is the particle soluble fraction needed for activation of particles having a dry diameter $d_{p, i}$ at a supersaturation $s$ (the reader is reminded that only particles having soluble volume fractions higher than a certain value are able to activate). Using Eq. (3), this relation can be further expressed as: $K_{i}(s)=1-$ $G R_{i}\left[g f_{i}\left(\varepsilon^{*}\right)\right]$. The relationship between $\varepsilon^{*}$ and $s$ is, in turn, obtained from Eq. (4). Using the equality of $A F_{i}^{*}$ and $K_{i}$ (see above), the relation linking $A F_{i}^{*}$ and $G R_{i}$ is consequently the following:

$$
\begin{aligned}
& A F_{i}^{*}(s)=K_{i}(s)=1-G R_{i}\left[h_{i}(s)\right], \\
& h_{i}(s)=\left(c_{i} k^{2} d_{p, i}^{-3} s^{-2}+1\right)^{1 / 3} .
\end{aligned}
$$

Brackets are used in (5) to indicate that the argument of $G R_{i}$ is another function, $h_{i}$, which maps a supersaturation $s$ to the HG factor of a particle having a critical supersaturation $s$ and a dry diameter $d_{p, i}$. In deriving Eq. (5), it was assumed that $\sigma$ and $v \phi$ are independent of the particle size. However, if the particle water-soluble fraction contains surface-active molecules, $\sigma$ depends on the solute concentration and hence also on the particle size (e.g. Adamson and Gast, 1997; Padró et al., 2007). Similarly the van't Hoff factor may also exhibit sensitivity to the particle size. For the sake of brevity, detailed discussion on this topic is postponed to Sect. 2.2. Explicit expressions for $G R_{i}$ in cases where the humidified particle distributions can be described with a Gaussian or log-normal distributions or a sum of them are presented in Appendix B.

The "effective" maximum supersaturation, $s_{\max }$, reached during the formation of observed cloud(s) can be estimated using Eq. (5) by minimizing the difference between the calculations and observations with respect to a chosen norm. We use the term "effective" to highlight the underlying assumption according to which the observed air masses share the same supersaturation history whereas atmospheric observations may represent an ensemble of different supersaturation histories. The assumption is necessary, however, given the experimental setup considered here. In the following, we estimate $s_{\max }$ using the Euclidean norm and thus minimize the following function:

$G(s)=\sqrt{\sum_{i=1}^{N}\left[A F_{i}^{*}(s)-A F_{i}\right]^{2}}$. 
The resulting activated fractions $A F_{i}^{*}\left(s_{\max }\right)$ can be compared with the measurements to evaluate the agreement between the observations and calculations.

Equation (5) can also be used to calculate the CCN spectrum:

$C C N_{\mathrm{tot}}(s)=\sum_{i=1}^{N} A F_{i}^{*}(s) C N_{\mathrm{tot}, i}$

In particular, $C C N_{\text {tot }}\left(s_{\max }\right)$ can be compared with the observational number of activated particles to test the agreement between the measurements and calculations. Independent measurements of CCN spectrum, if available, can be used in a closure study (see Snider et al., 2003, for example) by calculating $C C N_{\text {tot }}$ at the supersaturations used in $\mathrm{CCN}$ measurements. Equation (7) can also be applied to investigate the sensitivity of $\mathrm{CCN}$ concentrations to the particle hygroscopicity and/or mixing state by varying the values of the parameters which determine the distributions $G R_{i}$. Finally, Eqs. (5) and (7) serve as a parameterization of CCN spectra, and it can be used in computationally demanding aerosol and cloud models that utilize the sectional approach in describing the particle number size distribution. While the parameterization presented here is not as explicit as the previous approaches (e.g. Khvorostyanov and Curry, 2006, and references therein), it does not set any restrictions regarding the treatment of aerosol mixing state or hygroscopicity.

\subsection{Further considerations}

\subsubsection{Size dependent surface tension and Van't Hoff fac- tor}

Here we extend the above-presented method to a case where the surface tension and/or van't Hoff factor exhibits dependence on the particle size that arises from the presence of the water-soluble component of aerosols. Presenting a detailed treatment that addresses these issues is beyond the scope of this study, and it suffices to note that several frameworks for calculating the van't Hoff factor and surface tension exist (Shulman et al., 1996; Li et al., 1998; Nenes et al., 1998; Abdul-Razzak and Ghan, 2004; Sorjamaa et al., 2004). To maintain flexibility in this respect, we present an approximative scheme that can be used in connection with any chosen thermodynamic model.

First we note that certain thermodynamic methods require that the soluble fraction of particles is specified for each particle size class (e.g. Abdul-Razzak and Ghan, 2004). Since our approach is based on describing the particle watersolubility using continuous distributions (see Eq. 4), a representative value for the particle water-solubility is needed for each size class. An intuitive choice in this respect is the soluble fraction corresponding to the median growth factor, in particular when the humidified distributions are monomodal and relatively narrow (see Eq. 2). Once the model for calculating the surface tension and/or for the van't Hoff factor has been chosen along with the representative values of the needed parameters, the following scheme can be applied.

1. Calculate the particle critical diameter as well as the surface tensions and surface excesses of the water-soluble component, $\sigma_{i}$ and $\Gamma_{i}$, respectively, at the representative critical supersaturation for each particle size class. If size dependent dissociation is accounted for, also the van't Hoff factor is calculated separately for each size class.

2. Substitute $k$ in Eq. (4) with the following expression:

$k_{i}=2 f_{i}^{-1 / 2}\left(\frac{4}{3 R T}\right)^{3 / 2}\left(\frac{M_{w}}{\rho_{w}}\right)\left(\frac{M_{s}}{v_{i} \phi_{i} \rho_{s}}\right)^{1 / 2} \sigma_{i}^{3 / 2}$.

Here $f_{i}$ is the fraction of water-soluble matter that partitions into the bulk solution contained by particles in the size class $i$, and it can be calculated using $\Gamma_{i}$ (e.g. AbdulRazzak and Ghan, 2004). The parameter $f_{i}$ is introduced because the surface/bulk partitioning of the surface-active solute influences the Raoult's term in the Köhler equation and hence also the particle critical supersaturation (Sorjamaa et al., 2004). To account for this, we decrease the watersoluble volume fraction of particles by the amount of the water-soluble matter residing on the particle/droplet surface. If the surface/bulk partitioning is not taken into account, $f_{i}$ is set to the unity. The obtained expressions $k_{i}$ are then substituted for $k$ in Eq. (5) and the subsequent calculations are carried out as previously.

\subsubsection{Effects of entrainment and kinetic limitations}

A potentially important issue neglected above is the entrainment of cloud-free air into the air parcel where measurements were conducted (Noone et al., 1992; Mertes et al., 2005). There is no straightforward way to extend the method to account for entrainment in a quantitative manner. In groundbased studies, however, possible errors caused by a dilution of the measured air masses can be avoided by checking that the activated fraction of particles approaches unity at a diameter range $>300 \mathrm{~nm}$. This is because entrainment leads to a dilution of cloud air and hence to a partial activation of larger particles (Noone et al., 1992).

Another assumption behind the approach is that all particles having a critical supersaturation below $s_{\max }$ are incorporated into cloud droplets. Atmospheric cloud formation is, however, a dynamical process during which the water vapor concentration changes over relatively short timescales and therefore particles may not have enough time to grow to cloud droplet sizes (Chuang et al., 1997; Nenes et al., 2001). In order to quantify possible errors associated with these so-called kinetic limitations, the cloud formation has to be simulated explicitly with a dynamic model that requires information on the updraft velocity as an input (Pruppacher and Klett, 1997). Furthermore, the impact of kinetic limitations to the cloud droplet concentrations depends strongly on the updraft velocity near cloud base and thus this quantity has to be determined accurately (Nenes et al., 2001). 
This is difficult when operating in ground based platforms, however (Verheggen et al., 2007). For these reasons, it is not feasible to include a treatment of the kinetic limitations into the scheme. Here we suffice to note that regarding clean continental and marine air masses that prevailed during the field campaign discussed in this study, errors in the predicted number of cloud droplets are expected to be $15 \%$ at maximum (Nenes et al., 2001). This error range is comparable to the experimental errors in inferred fractions of activated particles (see Sect. 4).

\section{Experimental methods}

The second Pallas Cloud Experiment (2nd PaCE) took place at the Pallas Global Atmosphere Watch station in Northern Finland from 16 September 2005 to 6 October 2005 (location $67^{\circ} 58^{\prime} \mathrm{N}, 24^{\circ} 07^{\prime} \mathrm{E}$, see Komppula et al., 2005 for details). The station was inside the cloud cover for around one third of the campaign time and a wealth of data on the relationships between aerosols and cloud droplets was gathered. An overview of the experiment and its main results has been described in Komppula et al. (2006) and therefore only measurements that are directly relevant to the current study are described below.

The particle size distributions were measured with a dualinlet setup that allowed for determining the activated fraction of particles during cloud events. The first inlet sampled the total air which contained both residual and interstitial particles, whereas the second inlet was equipped with a $\mathrm{PM}_{2.5}$ cyclone to measure only the interstitial particle population. Total air inlet has the same construction as used and designed by Weingartner et al. (1999). The inlet consists of heated inlet and a heated snow-hood. The inlet design allows cloud droplets having a diameter $<40 \mu \mathrm{m}$ to enter the sampling line. The heating dries all cloud droplets as soon as they enter the sampling system and both cloud residual and interstitial particles are measured. According to the calculations of Weingartner et al. (1999), the sampling efficiency of the total inlet system is well above $95 \%$ in the size range 10 $40 \mu \mathrm{m}$ which is relevant for aerosol/cloud interaction studies. The fraction of activated particles was determined as a function of the particle size by comparing the particle concentrations from these two inlets (Komppula et al., 2005). Similar Differential Mobility Particle Sizer (DMPS) systems were used at both inlets for particle sizing at the dry particle diameter range 7-500 nm, and similar Condensation Particle Counters (CPC, model TSI 3010) operated at both inlets. A log-normal fit with two modes, corresponding to the Aitken and accumulation modes, was performed to the particle size distributions, and the number of activated particles was inferred separately for these two modes.

Hygroscopic properties of both the dried interstitial aerosol population, sampled with the $\mathrm{PM}_{2.5}$ inlet, and the total aerosol population, sampled with the total inlet, were measured with an H-TDMA instrument (Joutsensaari et al., 2001). The humidifier was kept at about $90 \%$ relative humidity, and the relative humidity of the aerosol flow was kept about 2-3\% lower than that of the sheath flow. The measurements errors are typically $1 \%$-unit for the water vapor saturation ratio and $2 \%$ for growth factors (Joutsensaari et al., 2001). The measured dry diameters were $30,50,80,100$ and $150 \mathrm{~nm}$. Hygroscopic growth of particles larger $150 \mathrm{~nm}$ in diameter was not measured due to technical problems associated with using larger voltages in the first DMA. A lognormal function was fitted to each humidified distribution and the performance of the fit was evaluated. The comparison showed that the chosen fit describes well the measurement data for the periods considered here.

The presence of clouds was verified from the relative humidity and visibility measurements (Vaisala FD12P weather sensor) as well as from photographs of the site taken automatically every 30 minutes for daytime periods. Moreover, the air mass history was evaluated by calculating the 5-day back trajectories for every three hours, or for every hour for cloud events lasting less than three hours, using the HYSPLIT model (Draxler and Rolph, 2003). The data were classified here according to the air mass history into three categories: continentally-influenced European ("EUR"), marine ("MARINE") and "mixed" air masses that have spent considerable amount of time both over sea and land ("MIX"). In order to be classified as a continental or marine case, the trajectory path had to have a clear history over the continent or the sea, respectively. If any indication of mixing of these two sources was observed, the trajectory was classified as a mixed case. This was done to differentiate continental and marine cases so that that the results would not be biased by mixing of the two source types. Example trajectories for each air mass type are shown in Fig. 1. As the figure illustrates, marine air masses originate typically from west or north while European air masses originate from south or east.

\section{Data analysis}

The measurement site was inside cloud for approximately $100 \mathrm{~h}$ during the experiment. The general features of the results are presented by Komppula et al. (2006). Four cloud events were chosen for a detailed case study using the approach described in Sect. 2. The aim of the case studies was to estimate the maximum supersaturation reached during the formation of observed cloud(s) and to provide more information on the role played by the mixing state and hygroscopicity in the cloud nucleating ability of atmospheric particles.

\subsection{Selected cases}

The initial data set was screened according to the following criteria to assure that the chosen cases would meet the assumptions behind the applied method: 1) no rainfall took 

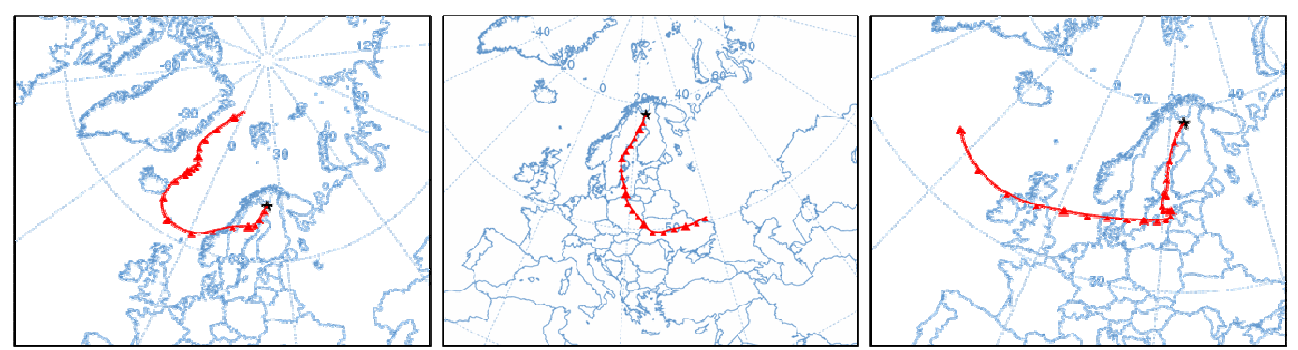

Fig. 1. Example trajectories for marine (left), continental (middle) and mixed (right) air masses Location of the measurement site is indicated using a star.

Table 1. General features of the analyzed cloud events. Here $N_{\text {tot }}$ and $N_{a c c}$ denote the total and accumulation mode particle concentrations, respectively, $A_{\text {tot }}$ and $A_{\text {acc }}$ denote the total number of activated particles and the number of activated accumulation mode particles, respectively, and $D_{50}$ is the diameter corresponding to the $50 \%$ activation efficiency. Shown are also ambient temperature $(T)$, wind speed (W), and the estimated peak supersaturation $\left(s_{\max }\right)$.

\begin{tabular}{lllll}
\hline Case & $\mathrm{A}$ & $\mathrm{B}$ & $\mathrm{C}$ & $\mathrm{D}$ \\
\hline Date & 23.9. & 28.9. & 29.9. & 29.9. \\
Time & $04: 00-07: 00$ & $23: 00-24: 00$ & $07: 00-08: 00$ & $19: 00-20: 00$ \\
Air mass & Marine & Mixed & European & Marine \\
$N_{\text {tot }}\left(\mathrm{cm}^{-3}\right)$, observational & 1834 & 930 & 479 & 279 \\
$N_{\text {acc }}\left(\mathrm{cm}^{-3}\right)$, observational & 320 & 473 & 199 & 54 \\
$N_{\text {acc }} / N_{\text {tot }}$ & 0.17 & 0.51 & 0.42 & 0.19 \\
$A_{\text {tot }}$, measured $\left(\mathrm{cm}^{-3}\right)$ & 228 & 399 & 140 & 36 \\
$A_{\text {tot }}$, calculated $\left(\mathrm{cm}^{-3}\right)$ & 206 & 402 & 124 & 29 \\
$A_{\text {tot }} / N_{\text {tot }}(\%)$ & 12 & 43 & 29 & 13 \\
$A_{\text {acc }} / A_{\text {tot }}(\%)$ & 50 & 84 & 73 & 48 \\
$D_{50}(\mathrm{~nm})$, observational & 115 & 121 & 139 & 141 \\
$T\left({ }^{\circ} \mathrm{C}\right)$ & 4.8 & 6.9 & 6.2 & 5.5 \\
W $(\mathrm{m} / \mathrm{s})$ & 7.4 & 5.0 & 3.7 & 1.8 \\
Visibility $(\mathrm{m})$ & 87 & 67 & 97 & 107 \\
$S_{\text {max }}$, calculated $(\%)$ & 0.26 & 0.21 & 0.18 & 0.24 \\
\hline
\end{tabular}

place during the period and 2) the fraction of activated particles was $>90 \%$ at the diameter range $>400 \mathrm{~nm}$. The former criterion was applied because raindrops scavenge interstitial particles and may thus bias the measurements (Komppula et al., 2005). The latter criterion was applied because smaller activated fractions might be caused by entrainment (Noone et al., 1992; Hallberg et al., 1998; Mertes et al., 2005). Another factor that could explain a partial activation of large particles is the presence of insoluble black carbon or dust particles (Hallberg et al., 1998). This cannot be verified, however, since the hygroscopic measurements covered only dry diameters up to $150 \mathrm{~nm}$ and thus associated uncertainties are avoided by applying the criterion. After the screening, four cases were selected from the remaining data set so that they cover the range of ambient conditions met during the experiment. Taken together, the cases represent different air masses, degrees of pollution as well as the scale of the observed aerosol and their activation characteristics. The total and interstitial particle size distributions for the chosen cases are displayed by Fig. 2 and the general features of the cases are shown in Table 1. A particularly interesting feature of the results is that Aitken mode particles made non-negligible contribution to the number of activated particles; their fractional contribution ranged from 16 to $52 \%$ (Table 1).

\subsection{Hygroscopic properties}

The dry diameters measured by the H-TDMA instrument and those measured by the DMPS set-up did not overlap, and therefore the hygroscopicity data were extra- and interpolated to the diameters at which the activation measurements were conducted. To this end, the available H-TDMA data for each case was averaged over the considered time interval (Table 2). Here the smallest measured particle size $(30 \mathrm{~nm})$ was not considered since particles with sizes $<50 \mathrm{~nm}$ are not expected to participate in the cloud formation under conditions relevant to this study. Here it is worth noting that 
Table 2. Hygroscopic growth factors of 50-150 nm particles for the four analyzed cloud cases.

\begin{tabular}{lllll}
\hline & \multicolumn{3}{c}{ Diameter } \\
CASE & 50 & 80 & 100 & 150 \\
\hline $\mathrm{A}$ & 1.14 & 1.15 & 1.19 & 1.25 \\
$\mathrm{~B}$ & 1.29 & 1.30 & 1.37 & 1.43 \\
$\mathrm{C}$ & 1.30 & 1.30 & 1.31 & 1.42 \\
$\mathrm{D}$ & 1.16 & 1.17 & 1.16 & 1.24 \\
\hline
\end{tabular}
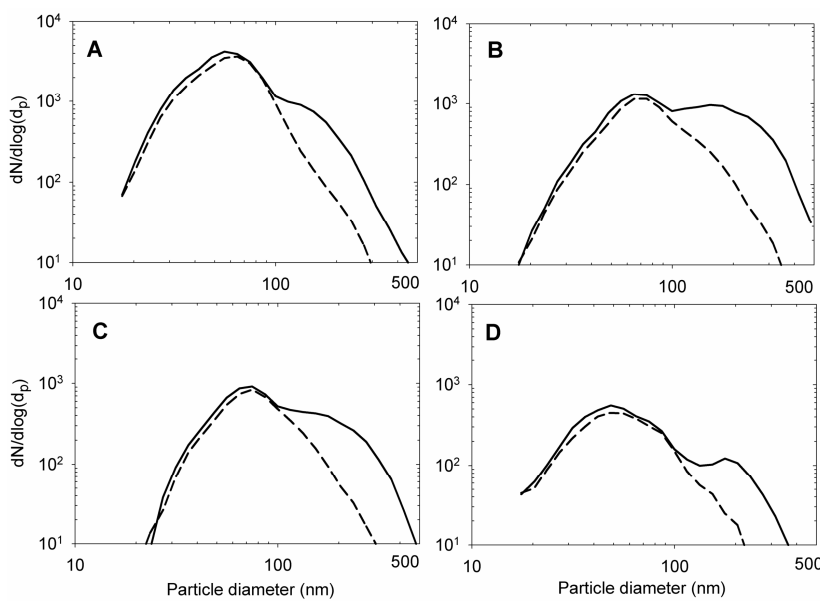

Fig. 2. The total and interstitial particle number size distribution (solid and dashed lines, respectively) for each analyzed cloud event. Please note the use of the logarithmic scales.

the humidified particle distributions exhibited only a single mode, whereas two distinct hygroscopic modes, termed typically as less and more hygroscopic modes, are often observed in ambient measurements (e.g. Cocker et al., 2001; Ferron et al., 2005). As also seen from the table, the mean HG factors range from 1.11 to 1.43 , corresponding to the soluble fraction range of $0.13-0.49$, and they tend to increase with increasing particle size.

The comparison of the measurement data and the performed fits is shown in Fig. 3. The function used in the fitting is of the following form $f(x)=a x^{b}$, where $x$ is the mean HG factor or the geometric standard deviation (GSD) of a humidified distribution, and $a$ and $b$ are the fitting parameters. As can be seen from Fig. 3, the performance of the fits was good and the extrapolated values are in a reasonable range. It is also worth noting that in all cases, particles are less hygroscopic than pure ammonium sulfate particles which have a HG factor of $\sim 1.77$ at the water activity of 0.90 (Tang and Munkelwitz, 1997).

The sensivity of the results to extrapolating the measurement data to the diameter range $>150 \mathrm{~nm}$ was assessed by repeating the calculations with the mean HG factors and GSDs

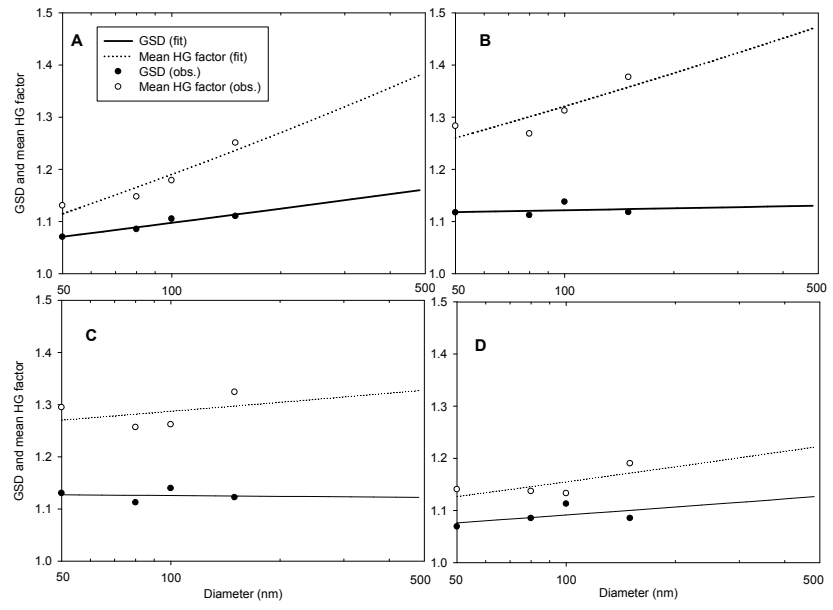

Fig. 3. The mean hygroscopic growth factors and their geometric standard deviation (GSD) based on the observed distributions (open and solid symbols, respectively) and the corresponding fits (dashed and solid lines, respectively).

set equal to those for $150 \mathrm{~nm}$ particles at the particle size range $>150 \mathrm{~nm}$. As a result, the estimated $s_{\max }$ and predicted number of activated particles change only up to 4 and $7 \%$, respectively. Such a small sensitivity gives indication that the following results are not affected by the lack of measurement data for $>150 \mathrm{~nm}$ particles.

One issue neglected so far is the fact that particles selected by the first DMA in an H-TDMA instrument do not have exactly the same size but consist of a width of sizes as determined by the transfer function of the instrument (Knutson and Whitby, 1975; Stolzenburg, 1988; Reischl, 1991). On the other hand, the considerations presented above assume that the only factor behind a spread in humidified particle distributions is heterogeneous chemical composition of particles having the same size. In order to quantify the relationship between the "real" GSD that corresponds to the humidified distribution of particles having a certain size $d_{p}$ and the observational GSD, which may reflect the chemical composition of particles with varying sizes, a series of calculations was performed as follows. First, we calculated the transfer functions characteristic to the DMA used in the experiments and fitted a log-normal function to the resulting particle size distributions. The values of GSDs of particle distributions passing through the first DMA, GSD 1 , were calculated to be $1.025,1.026$ and 1.028 for particles having a diameter 50,100 and $150 \mathrm{~nm}$, respectively. In the next step, the particle size distributions were treated as probability distributions and all size-selected particles passing through the first DMA were assumed to have the same chemical composition. Accordingly, it is easy to show that the "real" distribution of HG factors of particles with a size $d_{p}$ is $\mathrm{Y}=\mathrm{X}_{1}^{-1} \mathrm{X}_{2}$ where $\mathrm{X}_{1}$ is the probability distribution determined by the transfer function and $\mathrm{X}_{2}$ is the distribution corresponding to the measured 


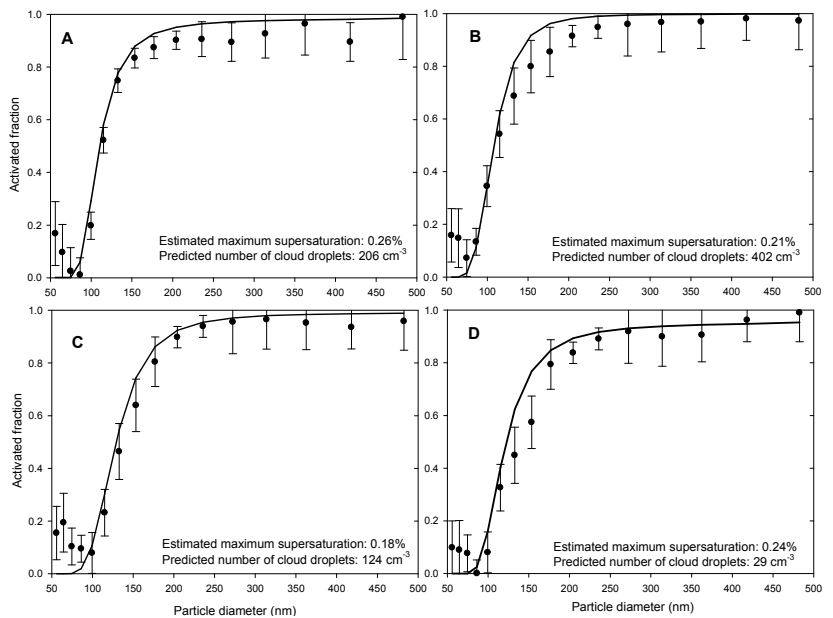

Fig. 4. The measured fractions of activated particles (symbols) and the predicted activated fractions (solid lines) for the considered cases. The error bars are based on the size-segregated concentration difference observed between the DMPSs measuring at different inlets during the non-cloudy period prior and after the cloud event. Also shown are the estimated maximum supersaturations and predicted number of cloud droplets for each case.

HG factors. We calculated the distribution Y using Monte Carlo methods for different values of $\mathrm{GSD}_{1}$, geometric standard deviation of the measured distribution, $\mathrm{GSD}_{2}$, and the mean HG factor of the humidified distribution. The results show that errors in calculating the "real" GSD are below 0.01 (in absolute scale) when $\mathrm{GSD}_{1}<1.04$ and $\mathrm{GSD}_{2}>1.05$ and that they are insensitive to the mean HG factor. Moreover, the absolute errors in the "real" value of GSD reach a value of 0.014 when $\mathrm{GSD}_{1}=1.04$ and $\mathrm{GSD}_{2}=1.05$. Keeping in mind that the values of $\mathrm{GSD}_{1}$ and $\mathrm{GSD}_{2}$ were consistently below 1.03 and above 1.05 , respectively, in our case, the results show that the issue considered here can be neglected in the subsequent considerations.

\subsection{Particle activation}

The measured fractions of activated particles are shown in Figure 4 for each case. The activation profiles share similar features with those of previous ground-based particle activation studies (Svenningsson et al., 1994, 1997; Martinsson et al., 1999; Mertes et al., 2005; Targino et al., 2007): the activated fractions start increase rapidly with the particle size at the size range $50-80 \mathrm{~nm}$, reach $>80 \%$ at the diameter range $150-200 \mathrm{~nm}$ and exhibit only slight increase at the diameter range $>200 \mathrm{~nm}$. In the considered cases, $D_{50}$, i.e. the diameter at which particles activate with 50\% efficiency, was estimated to lie in the range $112-141 \mathrm{~nm}$, being lowest in the case $\mathrm{A}$ and highest in $\mathrm{D}$. In comparison, $D_{50}$ varied between 88 and $215 \mathrm{~nm}$ during the whole experiment. It can be seen that the activated fraction fluctuated somewhat at the diameter range $<70-80 \mathrm{~nm}$. This is attributed to low parti- cle concentrations at the smallest size bins and to relatively rapid coagulational scavenging of ultrafine particles by cloud droplets (Komppula et al., 2005).

The peak supersaturations reached in the observed cloudy air masses, $s_{\max }$, were estimated as described in Sect. 2.1. The values of $s_{\max }$ as well as the predicted fractions of activated particles, calculated using Eqs. (5) and (B1), and the total number of activated particles, calculated with Eq. (7), are shown in Fig. 4 and in Table 1. The value of $s_{\max }$ is seen to vary between 0.18 and $0.26 \%$, being smallest in the case $\mathrm{C}$ and largest in the case $\mathrm{A}$. This range compares well with the values reported from previous ground based particle activation studies (Sveningsson et al., 1994, 1997; Martinsson et al., 1999; Mertes et al., 2005). Overall, the predicted fractions of activated particles were within or close to the error bars, excluding the smallest sizes in which the activated fractions fluctuated slightly due to the reasons discussed above. The predicted and observational number of particles incorporated into cloud droplets were within 9.6, $0.8,15.7$ and $17.1 \%$ in the cases A, B, C and D, respectively, which shows also good agreement (see Table 1). By comparing the size-dependent trends in the particle activation it can be seen that the method can also explain the case-varying steepness of the increase in the activated fractions in the size range $\sim 100-200 \mathrm{~nm}$ and the smaller, as compared to other cases, activated fractions of $>200 \mathrm{~nm}$ particles in the case D. The latter feature results from the smallest HG factors exhibited by the particles in the case D (Table 2). However, the calculations tended to overpredict slightly the measured fractions of activated particles especially in the size range $>150 \mathrm{~nm}$. A possible reason is that the hygroscopic properties of particles were not measured at this size range and thus the possible presence of hydrophobic particles, which may explain the overprediction, cannot be excluded. Additionally, there were only a small number of particles at the larger sizes which makes the results susceptible to fluctuations in the measured particle concentrations.

We note that the presented estimates of $s_{\max }$ apply only to the measured air masses and may not be representative of the sampled cloud(s) as a whole. For example, in ground-based studies, the measurements system may be located so close to cloud base that higher supersaturations than the observations imply are reached higher in the cloud air.

\subsection{Sensitivity studies}

A set of sensitivity calculations was performed to investigate how the particle activation behavior would change as a response to changes in the particle water uptake properties under the assumption that the peak supersaturation of water vapour is not affected. The calculations were done by varying the mean HG factors and/or GSDs while keeping the values of $s_{\max }$, estimated as described in the previous section, constant. 
Table 3. The total number of activated particles in different sensitivity scenarios and cases.

\begin{tabular}{lllll}
\hline & \multicolumn{5}{l}{ Case } \\
\hline & A & B & C & D \\
Base case & 224 & 402 & 118 & 29 \\
& & & & \\
Size averaged mean HGF & 228 & 401 & 117 & 28 \\
Size averaged GSD & 233 & 403 & 118 & 30 \\
Size averaged mean HGF \& GSD & 241 & 403 & 116 & 29 \\
& & & & \\
$1.1 \times$ HGF & 338 & 475 & 138 & 43 \\
$1.05 \times$ HGF & 280 & 440 & 157 & 37 \\
$0.95 \times$ HGF & 170 & 357 & 97 & 22 \\
$0.9 \times$ HGF & 119 & 305 & 75 & 14 \\
& & & & \\
$1.1 \times$ GSD & 250 & 387 & 119 & 30 \\
$1.05 \times$ GSD & 232 & 393 & 121 & 31 \\
$0.95 \times$ GSD & 232 & 409 & 119 & 31 \\
\hline
\end{tabular}

The first sensitivity study considered the importance of size-dependent variability in the particle hygroscopicity. This question has relevance, for example, to developing a simple and accurate parameterization of the cloud formation that can be used in atmospheric models (Medina et al., 2007; Kivekäs et al., 2008). Here we repeated the calculations based on Eqs. (5) and (7) but by using the size-averaged value(s) of the 1) mean HG factors, 2) GSDs of the humidified distributions, and 3) both mean HG factors and GSDs. The results are illustrated for the case A in Fig. 5 and the changes in the predicted number of activated particles are shown in Table 3. As can be seen, only small changes in the size dependent particle activation or in the total number of activated particles were predicted to occur as a result of size averaging. The relative changes in the total number of activated particles remained $<10 \%$ even for the case A which was most sensitive case in this regard. Regarding previous field studies, Medina et al. (2007) and Kuwata et al. (2008) conclude that accounting for the size-dependent chemical composition improves the closure between $\mathrm{CCN}$ measurements and Köhler calculations. In a similar study, Ervens et al. (2007) found that the accuracy of CCN predictions did not improve further upon introducing the available information on the size dependence of the chemical composition. Also Kivekäs et al. (2008) successfully parameterized the observational number of activated particles using a size-independent soluble mass fraction. Differing conclusions reached in these studies might be due to differing aerosol sources and properties. To further elucidate the importance of size varying particle chemical composition, future studies should explicitly address this issue through sensitivity studies.

The second sensitivity study focused on the impact of hygroscopicity to the particle cloud-nucleating ability. The cal-

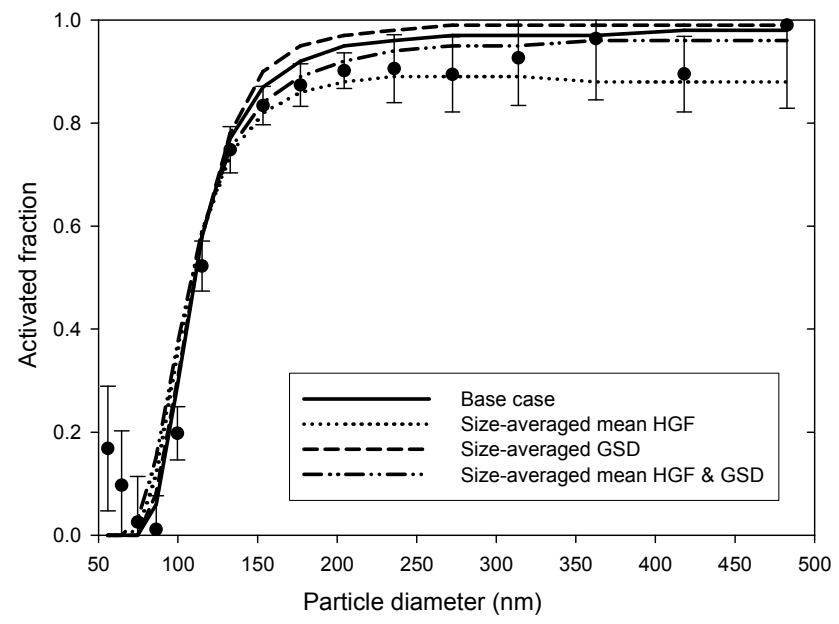

Fig. 5. The influence of size-averaging the particle hygroscopic properties on the particle activation for the case A. The measurements are displayed with symbols and the calculations are showed with lines as indicated in the legend.

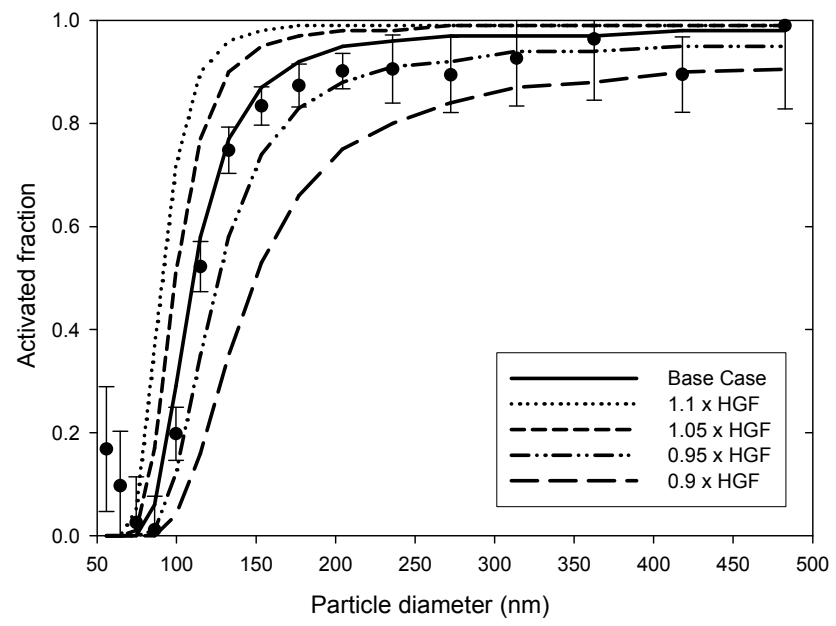

Fig. 6. Sensitivity of the particle activation to the mean HG factors for the case A. The sensitivity calculations were performed by multiplying the fit-based mean HG factors by a constant varying between 0.9 and 1.1 (shown in the legend).

culations were motivated by several recent studies that have addressed this topic (Dusek et al., 2006; Mochida et al., 2006; Ervens et al., 2007; Hudson et al., 2007; Quinn et al., 2008) and they were performed by increasing or decreasing the fit-based mean HG factors (Fig. 3) by 5 or $10 \%$ and repeating the activation calculations using Eq. (5). In comparison, 5 and $10 \%$ changes in the HG growth factor translate to changes of $\sim 16$ and $33 \%$ in the water-soluble volume fraction. The resulting size dependent activation is illustrated for case A in Figure 6 and the number of activated particles are shown in Table 3 for each case. Figure 6 shows that the size-dependent particle activation is highly sensitive to the 


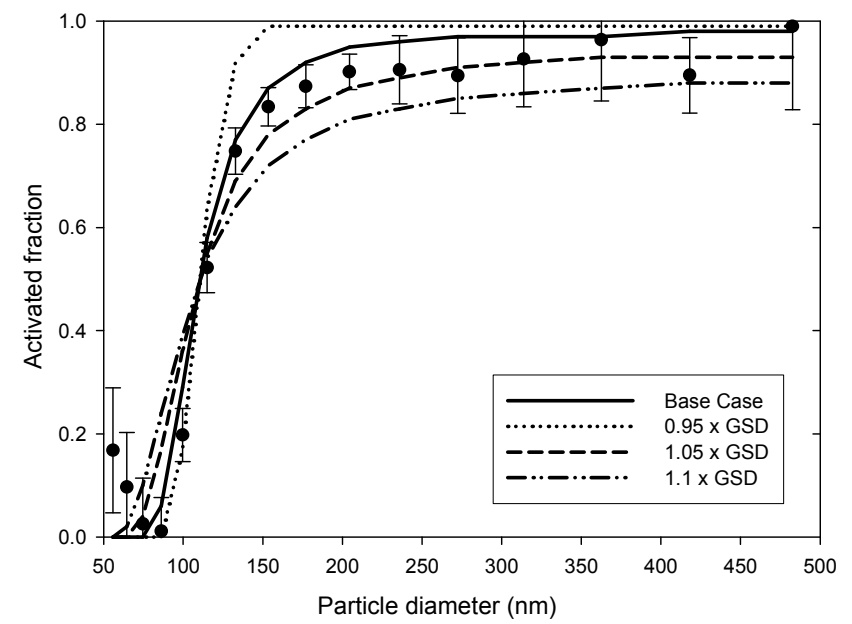

Fig. 7. Sensitivity of the particle activation to GSDs of the HG factor distributions for the case A. The sensitivity calculations were performed by multiplying the fit-based mean HG factors by a constant varying between 0.95 and 1.1 (shown in the legend).

particle hygroscopicity: even 5\% change in the mean $\mathrm{HG}$ factor resulted in clear deviations from the base case calculations. Overall, the largest changes are seen in the size range $100-200 \mathrm{~nm}$, and the value of $D_{50}$ is predicted to vary between $\sim 90$ and $150 \mathrm{~nm}$. As seen further from Table 3, large changes in the particle activation behavior were also predicted to occur in other cases. The calculated number concentrations of activated particles varied up to a factor of 2.8 , 1.6, 1.8 and 3.1 in the cases A, B, C and D, respectively. In addition, the cases D and $\mathrm{B}$ exhibited the largest and smallest sensitivity to the particle hygroscopicity, respectively, and these cases also featured the largest and smallest measured hygroscopic growth factors, respectively, among the considered cases (Table 2). Taken together, these results suggest that the $\mathrm{CCN}$ ability of a particle population having relatively small or moderate HG factors, as the case was here, is highly sensitive to the particle hygroscopicity. In view of the results of the studies referred above, there is no unambiguous answer at the present to what extent hygroscopic properties influence CCN ability of ambient particles - while some studies support our conclusion (e.g. Hudson et al., 2007; Quinn et al., 2008) there are also contrasting evidence (e.g. Dusek et al., 2006; Ervens et al., 2007).

The third and last sensitivity study investigated the influence of the particle mixing state on the particle activation, which is also a topic of active research (Broekhuizen et al., 2006; Rissmann et al., 2006; Ervens et al., 2007; Stroud et al., 2007). The influence of the mixing state was quantified by increasing the values of the fitted GSDs, shown in Fig. 2, by 5 or $10 \%$ as well as by decreasing them by $5 \%$, and carrying out the calculations as previously. Larger decreases are not considered here because they would lead to unrealistically small GSD values. The rationale behind this approach is that wider humidified distributions reflect more heterogeneous chemical composition of particles whereas the opposite holds for narrower distributions. The predicted sizedependent activation behavior is illustrated in Fig. 7 for case $\mathrm{A}$ and the number activated particles are shown in Table 3. Most notable feature displayed by Fig. 7 is that the heterogeneity in the chemical composition is reflected in the steepness of the activation curves: when only a narrow range of critical supersaturations are present in each particle size, the activation curve resembles a step function whereas more gradual changes are seen when each particle size contains a spread of critical supersaturations. All curves are also seen to intersect at the point corresponding to $D_{50}$ since the shape of the distribution of critical supersaturations does not play a role at $50 \%$ activation efficiency. Furthermore, Table 3 shows that the total number of activated particles is insensitive to the value of GSD. This is because the activated fractions of particles with sizes smaller and larger than $D_{50}$ respond in an opposite manner to changes in GSD. To conclude with, non-negligible changes in size-dependent particle activation are predicted to take place in response to changes in the particle mixing state, and thus the steepness of the "S"-shaped activation profiles may carry information on the particle mixing state, as suggested previously by Martinsson et al. (1999) and Mertes et al. (2005). Several recent CCN closure studies have investigated how sensitive $\mathrm{CCN}$ predictions are to the aerosol mixing state but the conclusions differ; for example, Ervens et al. (2007) found that the mixing state is of second importance in predicting $\mathrm{CCN}$ concentrations while Stroud et al. (2007) and Broekhuizen et al. (2006) concluded that accounting for external mixing improves $\mathrm{CCN}$ closure. In addition, according to the cloud model calculations performed by O'Dowd et al. (2004), the aerosol mixing state is important for predicting particle activation in marine environment.

It is worth noting that $s_{\max }$ was not adjusted to changing aerosol properties but was kept constant in all sensitivity scenarios. For example, if particles are more hygroscopic, they will deplete more water vapor during the cloud formation and thereby increased particle hygroscopicity leads to smaller peak supersaturations and hence smaller number of activated particles. As discussed in Sect. 2.2.3, however, accounting for such "dampening" dynamical responses is beyond the scope of the method and therefore the presented estimates on the importance of the considered factors represent probably upper limit estimates.

\section{Summary and conclusions}

We derived an algorithm for analyzing the influence of the particle chemical composition and mixing state (in terms of the water uptake) on the cloud nucleation ability of atmospheric particles on the basis of size-resolved measurements of particle activation and hygroscopic growth. The method 
provides also a quantitative estimate of the peak supersaturation of water vapour reached during the formation of the observed cloud(s). No assumptions regarding the shape of the humidified particle distributions are required, but if particle diameters for which activation and water uptake measurements were conducted are not the same, inter- or extrapolation of the measurement data is necessary. The equations derived here also provide a flexible parameterization of CCN spectra that can be used in computationally demanding aerosol and cloud models. As a further application, the method can be used to compliment $\mathrm{CCN}$ closure studies.

The method was applied in interpreting results of a measurement campaign that focused on aerosol-cloud interactions taking place at a subarctic background site. A set of case studies was conducted, and the size-dependent activation trends could be successfully explained by a maximum supersaturation that varied between 0.18 and $0.26 \%$ depending on the case. There was no indication on the presence of organic films on particles that would be able to suppress condensation of water vapour nor any clear evidence on variations in the peak supersaturation, in contrast to the results of a study by Mertes et al. (2005). Furthermore, the conducted analysis showed that the activated fractions and the total number of particles acting as $\mathrm{CCN}$ are expected to be highly sensitive to the particle hygroscopicity; for example, the latter quantity varied by a factor of 1.8-3.1, depending on the case, when the mean hygroscopic growth factors were varied by $10 \%$. Here it should be noted that the particles were only moderately hygroscopic with hygroscopic growth factors varying between 1.1 and 1.4. Another important conclusion that can be drawn from the case studies is that the size-dependent activation profiles may carry information on the mixing state of particles. This was demonstrated by a sensitivity study where the parameter describing the spread in the water-solubility of particles having the same dry size was varied. The results show that the steepness of the calculated activation curves changes notably in response to changes in the mixing state.

\section{Appendix A}

\section{List of the key symbols used in Sect. 2}

$\boldsymbol{A} \boldsymbol{F}_{i}-$ The measured fraction of activated particles in the size class $i$.

$\boldsymbol{A} \boldsymbol{F}_{i}{ }^{*}$ - The predicted fraction of activated particles in the size class $i$.

$\boldsymbol{C} \boldsymbol{N}_{\text {tot, } i}$ - The measured particle number concentration in the size class $i$.

$\boldsymbol{C} \boldsymbol{N}_{i}\left(\boldsymbol{s}_{c}<\boldsymbol{s}\right)$ - The number concentration of particles having a critical supersaturation below $s$ in the size class $i$. $\boldsymbol{d}_{p, i}$ - The dry diameter of particles in the size class $i$.

$\boldsymbol{G} \boldsymbol{R}_{i}$ - The normalized cumulative distribution of the hygroscopic growth factors of the particles in the size class $i$.

$\boldsymbol{K}_{i}$ - The fraction of particles in the size class $i$ that are activated according to the Köhler theory at a supersaturation $s\left(K_{i}(s)=C \mathrm{~N}_{i}\left(s_{c}<s\right) / C \boldsymbol{N}_{\text {tot }, i}\right)$.

$\boldsymbol{s}_{\max }-$ The maximum supersaturation, estimated using the approach described in Sect. 2, that is reached in the observed cloud(s).

$\boldsymbol{S} \boldsymbol{F}_{i}$ - The normalized cumulative distribution of the water-soluble volume fraction of particles in the size class $i$.

$\boldsymbol{G S D}$ - Geometric standard deviation.

\section{Appendix B}

\section{Expressions for the cumulative distributions of hy- groscopic growth factors}

The humidified particle size distributions measured by the second DMA in H-TDMA instrument can be often described by a log-normal or Gaussian distribution(s). In the former case, the function $G R_{i}$ in (5) is the following:

$G R_{i}\left[h_{i}(s)\right]=\frac{1}{2}+\frac{1}{2} \operatorname{erf}\left[\frac{\ln \left[h_{i}(s)\right]-\ln \left(g^{*}\right)}{\sqrt{2} \ln \left(\sigma_{g}\right)}\right]$,

where $g^{*}$ and $\sigma_{g}$ are the mean growth factor and the geometric standard deviation of the mode, respectively. When the humidified distribution is a Gaussian, $G R_{i}$ has the following functional form:

$G R_{i}\left[h_{i}(s)\right]=\frac{1}{2}+\frac{1}{2} \operatorname{erf}\left[\frac{h_{i}(s)-g^{*}}{\sqrt{2} \sigma_{g}}\right]$

Equations (B1) and (B2) can be generalized to cases where the particles exhibit multi-modal growth behavior by summing the corresponding cumulative distributions and weighting them with the corresponding fractional particle concentrations. Furthermore, it should be noted that if the diameters which are selected by the first DMA in H-TDMA instrument do not match the diameters at which the activated fractions are determined, the observational values of $g^{*}$ and $\sigma_{g}$ need to be extra- or interpolated to these diameters. An example of such fitting procedure is given in Sect. 4. 
Acknowledgements. The work has been supported financially by the EC projects ACCENT (European Network of Excellence in Atmospheric Composition Change) and EUSAAR (European Supersites for Atmospheric Aerosol Research), as well as by the Maj and Tor Nessling Foundation. One of the authors (T. A.) acknowledges financial support from the Emil Aaltonen Foundation.

Edited by: A. Nenes

\section{References}

Abdul-Razzak, H. and Ghan, S.: A parameterization of aerosol activation: 2. Multiple aerosol types, J. Geophys. Res., 105(D6), 6837-6844, 2000.

Abdul-Razzak, H. Ghan, S. J.: Parameterization of the influence of surface-active organics on aerosol activation, J. Geophys. Res, 109, D03205, doi:10.1029/2003JD004043, 2004.

Adamson, A. W., Gast, A. P.: Physical Chemistry of Surfaces. John Wiley \& Sons Inc., USA, 1997.

Broekhuizen, K., Chang, R., Leaitch, W., Li, S., and Abbatt, J. P. D.: Closure between measured and modeled cloud condensation nuclei $(\mathrm{CCN})$ using size-resolved aerosol compositions in downtown Toronto, Atmos. Chem. Phys., 6, 2513-2524, 2006, http://www.atmos-chem-phys.net/6/2513/2006/.

Chen, Y. and Penner, J. E.: Uncertainty analysis for estimates of the first indirect aerosol effect, Atmos. Chem. Phys., 5, 2935-2948, 2005, http://www.atmos-chem-phys.net/5/2935/2005/.

Chuang, P., Charlson, R., and Seinfeld, J.: Kinetic limitation on droplet formation in clouds, Nature, 390, 594-596, 1997.

Cocker III, D. R., Whitlock, N. E., Flanagan, R. C., and Seinfeld, J. H.: Hygroscopic properties of Pasadena, California aerosol, Aerosol Sci. Tech., 35, 637-647, 2001.

Cohard, J.-M., Pinty, J.-P., and Suhre, K.: On the parameterization of activation spectra from cloud condensation nuclei microphysical properties, J. Geophys. Res., 105(D9), 11753-11766, 2000.

Dusek, U., Frank, G. P., Hildebrandt, L., Curtius, J., Schneider, J., Walter, S., Chand, D., Drewnick, F., Hings, S., Jung, D., Borrmann, S., and Andreae, M. O.: Size matters more than chemistry for cloud-nucleating ability of aerosol particles, Science, 312, 1375-1378, 2006.

Draxler, R. R. and Rolph, G. D.: HYSPLIT (HYbrid Single-Particle Lagrangian Integrated Trajectory) Model access via NOAA ARL READY Website (http://www.arl.noaa.gov/ready/hysplit4.html), NOAA Air Resources Laboratory, Silver Spring, MD, USA, 2003.

Ervens, B., Cubison, M., Andrews, E., Feingold, G., Ogren, J. A., Jimenez, J.L., DeCarlo, P., and Nenes, A.: Prediction of cloud condensation nucleus number concentration using measurements of aerosol size distributions and composition and light scattering enhancement due to humidity, J. Geophys. Res., 112, D10S32, doi:10.1029/2006JD007426, 2007.

Ferron, G. A., Karg, E., Busch, B., and Heyder, J.: Ambient particles at an urban, semi-urban and rural site in Central Europe: Hygroscopic properties, Atmos. Env., 39, 343-352, 2005.

Gasparini, R., Collins, D. R., Andrews, E., Sheridan, P. J., Ogren, J. A., and Hudson, J. G.: Coupling aerosol size distributions and size-resolved hygroscopicity to predict humidity-dependent optical properties and cloud condensation nuclei spectra, J. Geophys. Res., 111, D05S13, doi:10.1029/2005JD006092, 2006.
Ghan, S. J. and Schwartz, S. E.: Aerosol properties and processes - A path from field and and laboratory measurements to global climate models, B. Am. Meteorol. Soc., 88, 1059-1083, 2007.

Hallberg, A., Noone, K. J., and Ogren, J. A.: Aerosol particles and clouds: which particles form cloud droplets?, Tellus, 50B, 5975, 1998.

Henning, S., Weingartner, E., Schmid, S., Wendisch, M., Gäggeler, H. W., and Baltensberger, U.: Size-dependent aerosol activation at the high-alpine site Jungfraujoch $(3580 \mathrm{~m}$ asl), Tellus, 54B, 82-95, 2002.

Hudson, J. G.: Variability of the relationship between particle size and cloud-nucleating ability, Geophys. Res. Lett., 34, L08801, doi:10.1029/2006GL028850, 2007.

IPCC. Climate Change 2007: The Physical Science Basis. Contribution of Working Group I to the Fourth Assessment Report of the Intergovernmental Panel on Climate Change, edited by: Solomon, S., Qin, D., and Manning, M., 2007.

Joutsensaari, J., Vaattovaara, P., Vesterinen, M., Hämeri, K. and Laaksonen, A.: A novel tandem differential mobility analyzer with organic vapor treatment of aerosol particles, Atmos. Chem. Phys., 1, 51-60, 2001, http://www.atmos-chemphys.net/1/51/2001/.

Khvorostyanov, V. I. and Curry, J. A.: Aerosol size spectra and CCN activity spectra: Reconciling the lognormal, algebraic, and power laws, J. Geophys. Res., 111, D12202, doi:10.1029/2005JD006532, 2006.

Kivekäs, N., Kerminen, V.-M., Anttila, T., Korhonen, H., Lihavainen, H., Komppula, M., and Kulmala, M.: Parameterization of cloud droplet activation using a simplified treatment of the aerosol number size distribution. J. Geophys. Res., 113, D15207, doi:10.1029/2007JD009485.

Knutson, E. O. and Whitby, K. T.: Aerosol classification by electric mobility: Apparatus, theory, and applications, J. Aerosol Sci., 6, 443-451, 1975.

Komppula, M., Lihavainen, H., Kerminen, V-M., Kulmala, M., and Viisanen, Y.: Measurements of cloud droplet activation of aerosol particles at a clean subarctic background site, J. Geophys. Res., 110, D06204, doi:10.1029/2004JD005200, 2005.

Komppula, M., Lihavainen, H., Hyvärinen, A.-P., Kerminen, V.-M., Aaltonen, V., Engler, C., Kivekäs, N., Leskinen, A., Vaattovaara, P., Rautiainen, J., Miettinen, P., Tiitta, P., Sorjamaa, R., Hillamo, R., Makkonen, U., Viisanen, Y., and Laaksonen, A.: Physical and chemical properties of aerosol particles and cloud droplets during the Second Pallas Cloud Experiment (Second PaCE), Proceedings of the 7th International Aerosol Conference edited by: Biswas, P., Chen, D. R., and Hering, S., St. Paul, USA, 10-15 September 2006, 1352-1353, 2006.

Kreidenweis, S. M., Koehler, K., DeMott, P. J., Prenni, A. J., Carrico, C., and Ervens, B.: Water activity and activation diameters from hygroscopicity data - Part I: Theory and application to inorganic salts, Atmos. Chem. Phys., 5, 1357-1370, 2005, http://www.atmos-chem-phys.net/5/1357/2005/.

Kuwata, M., Kondo, Y., Miyazaki, Y., Komazaki, Y., Kim, J. H., Yum, S. S., Tanimoto, H., and Matsueda, H.: Cloud condensation nuclei activity at Jeju Island, Korea in spring 2005, Atmos. Chem. Phys., 8, 2933-2948, 2008, http://www.atmos-chem-phys.net/8/2933/2008/.

Li, Z., Williams, A. L., and Rood, M. J.: Influence of soluble surfactant properties on the activation of aerosol particles containing 
inorganic solute, J. Atmos. Sci., 55, 1859-1866, 1998.

Lohmann, U., Quaas, J., Kinne, S., and Feichter, J.: Different approaches for constraining global climate models of the anthropogenic indirect aerosol effect, Bul. Am. Meteorol. Soc., 88, 243-249, 2007.

Martinsson, B., Frank, G., Cederfelt, S.-I., Swietlicki, E., Berg, O., Zhou, J., Bower, K. N., Bradbury, C., Birmili, W., Stratmann, F., Wendisch, M., Wiedensohler, A., and Yuskiewicz, B.: Droplet nucleation and growth in orographic clouds in relation to the aerosol population, Atmos. Res., 50, 289-315, 1999.

McFiggans, G., Artaxo, P., Baltensperger, U., Coe, H., Facchini, M. C., Feingold, G., Fuzzi, S., Gysel, M., Laaksonen, A., Lohmann, U., Mentel, T. F., Murphy, D. M., O’Dowd, C. D., Snider, J. R., and Weingartner, E.: The effect of physical and chemical aerosol properties on warm cloud droplet activation, Atmos. Chem. Phys., 6, 2593-2649, 2006,

http://www.atmos-chem-phys.net/6/2593/2006/.

McMurry, P. H.: A review of atmospheric aerosol measurements, Atmos. Environ., 34, 1959-1999, 2000.

Medina, J., Nenes, A., Sotiropoulou, R. P., Cottrell, L. D., Ziemba, L. D., Beckman, P. J., and Griffin, R. J.: Cloud condensation nuclei closure during the International Consortium for Atmospheric Research on Transport and Transformation 2004 campaign: Effects of size-resolved composition, J. Geophys. Res., 112, D10S31, doi:10.1029/2006JD007588, 2007.

Mertes, S., Lehmann, K., Nowak, A., Massling, A., and Wiedensohler, A.: Link between aerosol hygroscopic growth and droplet activation observed for hill-capped clouds at connected flow conditions during FEBUKO, Atmos. Env., 39, 4247-4256, 2005.

Ming, Y., Ramaswamy, V., Donner, L. J., and Phillips, V. T. J.: A new parameterization of cloud droplet activation applicable to general circulation models, J. Atmos. Sci., 63, 1348-1356, 2006.

Mochida, M., Kuwata, M., Miyakawa, T., Takegawa, N., Kawamura, K., and Kondo, Y.: Relationship between hygroscopicity and cloud condensation nuclei activity for urban aerosols in Tokyo, J. Geophys. Res, 111, D23204, doi:10.1029/2005JD006980, 2006.

Nenes, A., Pandis, S. N., and Pilinis, C.: ISORROPIA: a new thermodynamic model for inorganic multicomponent atmospheric aerosols, Aq. Geochem., 4, 123-152, 1998.

Nenes A., Ghan S., Abdul-Razzak, H., Chuang, P. Y., and Seinfeld, J. H.: Kinetic limitations on cloud droplet formation and impact on cloud albedo. Tellus, 53B, 133-149, 2001.

Nenes, A. and Seinfeld, J. H.: Parameterization of cloud droplet formation in global climate models, J. Geophys. Res., 108(D14), 4415, doi:10.1029/2002JD002911, 2003.

Noone, K. J., Ogren, J. A., Hallberg, A., Heintzenberg, J., Ström, J., Hansson, H.-C., Svenningsson, I. B., Wiedensohler, A., Fuzzi, S., Facchini, M. C., Arends, B. G., and Berner, A.: Changes in aerosol size- and phase distributions due to physical and chemical processes in fog, Tellus B44, 489-504, 1992.

O’Dowd, C. D., Facchini, M. C., Cavalli, F., Ceburnis, D., Mircea, M., Decesari, S., Fuzzi, S., Yoon, Y. J., and Putaud, J. P.: Biogenically-driven organic contribution to marine aerosol, Nature, 431, 676-680, doi:10.1038/nature02959, 2004.

Padró, L. T., Asa-Awuku, A., Morisson, R., and Nenes, A.: Inferring thermodynamic properties from $\mathrm{CCN}$ activation experiments a) single-component and binary aerosols, Atmos. Chem.
Phys., 7, 5263-5274, 2007,

http://www.atmos-chem-phys.net/7/5263/2007/.

Petters, M. D. and S. M. Kreidenweis, S. M.: A single parameter representation of hygroscopic growth and cloud condensation nucleus activity, Atmos. Chem. Phys., 7, 1961-1971, 2007, http://www.atmos-chem-phys.net/7/1961/2007/.

Pruppacher, H. R. and Klett, J. D.: Microphysics of Clouds and Precipitation. 2nd ed. Kluwer Academic, New York, USA, 1997.

Quinn, P. K., Bates, T. S., Coffman, D. J., and Covert, D. S.: In?uence of particle size and chemistry on the cloud nucleating properties of aerosols, Atmos. Chem. Phys., 8, 1029-1042, 2008, http://www.atmos-chem-phys.net/8/1029/2008/.

Reischl, G. P.: Measurement of ambient aerosols by the different mobility analyzer method: concepts and realization criteria for the size range between 2 and $500 \mathrm{~nm}$, Aerosol Sci. Technol., 14, 5-24, 1991.

Rissler, J., Swietlicki, E., Zhou, J., Roberts, G., Andreae, M. O., Gatti, L. V., and Artaxo, P.: Physical properties of the submicrometer aerosol over the Amazon rain forest during the wetto-dry season transition - comparison of modeled and measured CCN concentrations. Atmos. Chem. Phys., 4, 2119-2143, 2004, http://www.atmos-chem-phys.net/4/2119/2004/.

Rissman, T. A., VanReken, T. M., Wang, J., Gasparini, R., Collins, D. R., Jonsson, H. H. Brechtel, F. J., Flagan, R. C., and Seinfeld, J. H.: Characterization of ambient aerosol from measurements of cloud condensation nuclei during the 2003 Atmospheric Radiation Measurement Aerosol Intensive Observational Period at the Southern Great Plains site in Oklahoma, J. Geophys. Res., 111, D05S11, doi:10.1029/2004JD005695, 2006.

Shulman, M. L., Jacobson, M. C., Charlson, R. J., Synovec, R. E., and Young, T. E.: Dissolution behaviour and surface tension effects of organic compounds in nucleating cloud droplets, Geophys. Res. Lett., 23, 277-280, 1996.

Snider, J. R., Guibert, S., Brenguier, J.-L., and Putaud, J.-P.: Aerosol activation in marine stratocumulus clouds: 2. Köhler and parcel theory closure studies. J. Geophys. Res., 108, 8629, doi:10.1029/2002JD002692, 2003.

Sorjamaa, R., Svenningsson, B., Raatikainen, T., Henning, S., Bilde, M., and Laaksonen, A.: The role of surfactants in Köhler theory reconsidered, Atmos. Chem. Phys., 4, 2107-2117, 2004, http://www.atmos-chem-phys.net/4/2107/2004/.

Stoltzenburg, M. R. :An ultrafine aerosol size distribution measuring system, Ph.D. Thesis, University of Minnesota, 1998.

Stroud, C. A., Nenes, A., Jimenez, J. L., DeCarlo, P. F., Alex Huffman, J., Bruintjes, R. Nemitz, E., Delia, A. E., Toohey, D. W., Guenther, A. B., and Nandi, S.: Cloud Activating Properties of Aerosol Observed during CELTIC, J. Atmos. Sci., 64, 441-459, 2007.

Svenningsson, B., Hansson, H.-C., Wiedensohler, A., Noone, K. J., Ogren, J. A., Hallberg, A., and Colvile, R.: Hygroscopic growth of aerosol particles and its influence on nucleation scavenging in cloud: experimental results from Kleiner Feldberg, J. Atmos. Chem., 19, 129-151, 1994.

Svenningsson, B., Hansson, H.-C., Martinsson, B., Wiedensohler, A., Swietlicki, E., Cederfelt, S.-I., Wendisch, M., Bower, K. N., Choularton, T. W., and Colvile, R. N.: Cloud droplet nucleation scavenging in relation to the size and hygroscopic behaviour of aerosol particles, Atmos. Env., 31, 2463-2475, 1997.

Swietlicki E., Zhou, J., Berg, O. H., Martinsson, B. G., Frank, G., 
Cederfelt, S.-I., Dusek, U., Berner, A., Birmili, W., Wiedensohler, A., Yuskiewicz, B., and Bower, K. N.: A closure study of sub-micrometer aerosol particle hygroscopic behaviour, Atmos. Res., 50, 205-240, 1999.

Tang, I. N. and Munkelwitz, H. R.: Water activities, densities, and refractive indices of aqueous sulfates and sodium nitrate droplets of atmospheric importance, J. Geophys. Res. 99, 18801-18808, 1994.

Targino A. C., Noone, K. J., Drewnick, F., Schneider, J., Krejci, R., Olivares, G., Hings, S., and Borrmann, S. Microphysical and chemical characteristics of cloud droplet residuals and interstitial particles in continental stratocumulus clouds, Atmos. Res., 86, 225-240, 2007.

Weingartner, E., Nyeki, S., and Baltensperger, U.: Seasonal and diurnal variation of aerosol size distributions $(10<D<750 \mathrm{~nm})$ at a high-alpine site (Jungfraujoch $3580 \mathrm{~m}$ asl), J. Geophys. Res., 104, 26809-26820, 1999.
Verheggen, B., Cozic, J., Weingartner, E., Bower, K., Mertes, S., Connolly, P., Gallagher, M., Flynn, M., Choularton, T., and Baltensperger, U.: Aerosol partitioning between the interstitial and condensed phase in mixed-phase clouds, J. Geophys. Res., 112, D23202, doi:10.1029/2007JD008714, 2007.

Ziese, M., Wex, H., Nilsson, E., Salma, I., Ocskay, R., Hennig, T., Massling, A., and Stratmann, F.: Hygroscopic growth and activation of HULIS particles: Experimental data and a new iterative parameterization scheme for complex aerosol particles. Atmos. Chem. Phys., 8, 1855-1866, 2008,

http://www.atmos-chem-phys.net/8/1855/2008/. 